\title{
Chromium acetate stimulates adipogenesis through regulation of gene expression and phosphorylation of adenosine monophosphate-activated protein kinase in bovine intramuscular or subcutaneous adipocytes
}

\author{
Jongkyoo Kim ${ }^{1, a}$, Kiyong Chung ${ }^{2,3, a}$, and Bradley J. Johnson ${ }^{1, *}$
}

* Corresponding Author: Bradley J. Johnson Tel: +1-806-834-7057, Fax: +1-806-742-4003,

E-mail: bradley.johnson@ttu.edu

${ }^{1}$ Department of Animal and Food Sciences, Texas Tech University, Lubbock, TX 79409, USA

2 National Institute of Animal Science, Hanwoo Experiment Station, Pyeongchang 25340, Korea

${ }^{3}$ Korea National College of Agriculture and Fisheries, Jeonju 54874, Korea

a Kim and Chung made equal contributions to this manuscript.

ORCID

Jongkyoo Kim

https://orcid.org/0000-0002-4827-5762

Kiyong Chung

https://orcid.org/0000-0003-0957-875X

Bradley J. Johnson

https://orcid.org/0000-0002-8445-2578

Submitted Feb 1, 2019; Revised May 1, 2019; Accepted Jul 9, 2019
Objective: We hypothesized that $\mathrm{Cr}$ source can alter adipogenic-related transcriptional regulations and cell signaling. Therefore, the objective of the study was to evaluate the biological effects of chromium acetate ( $\mathrm{CrAc}$ ) on bovine intramuscular (IM) and subcutaneous (SC) adipose cells.

Methods: Bovine preadipocytes isolated from two different adipose tissue depots; IM and $\mathrm{SC}$ were used to evaluate the effect of CrAc treatment during differentiation on adipogenic gene expression. Adipocytes were incubated with various doses of CrAc: 0 (differentiation media only, control), $0.1,1$, and $10 \mu \mathrm{M}$. Cells were harvested and then analyzed by real-time quantitative polymerase chain reaction in order to measure the quantity of adenosine monophosphate-activated protein kinase- $\alpha(A M P K-\alpha)$, CCAAT enhancer binding protein- $\beta(C /$ $E B P \beta), G$ protein-coupled receptor 41 (GPR41), GPR43, peroxisome proliferator-activated receptor- $\gamma(P P A R \gamma)$, and stearoyl CoA desaturase $(S C D)$ mRNA relative to ribosomal protein subunit 9 (RPS9). The ratio of phosphorylated-AMPK (pAMPK) to AMPK was determined using a western blot technique in order to determine changing concentration.

Results: The high dose $(10 \mu \mathrm{M})$ of CrAc increased $C / E B P \beta$, in both IM $(\mathrm{p}=0.02)$ and SC $(\mathrm{p}=0.02)$. Expression of $P P A R \gamma$ was upregulated by $10 \mu \mathrm{M}$ of CrAc in IM but not in SC. Expression of SCD was also increased in both IM and SC with $10 \mu \mathrm{M}$ of CrAc treatment. Addition of CrAc did not alter gene expression of glucose transporter 4, GPR41, or GPR43 in both IM and SC adipocytes. Addition of CrAc, resulted in a decreased pAMPKa to AMPKa ration $(\mathrm{p}<0.01)$ in IM.

Conclusion: These data may indicate that $\mathrm{Cr}$ source may influence lipid filling in IM adipocytes via inhibitory action of AMPK phosphorylation and upregulating expression of adipogenic genes.

Keywords: AMP-activated Protein Kinase; Bovine Adipocyte; Chromium Acetate

\section{INTRODUCTION}

Chromium (Cr) is the 21st most abundant mineral on earth and is primarily found as divalent $\mathrm{Cr}\left(\mathrm{Cr}^{2+}\right)$, trivalent $\mathrm{Cr}\left(\mathrm{Cr}^{3+}\right)$, or hexavalent $\mathrm{Cr}\left(\mathrm{Cr}^{6+}\right)$ in nature [1,2]. Due to poor absorption of inorganic forms of $\mathrm{Cr}$ such as chromic chloride $\left(\mathrm{CrCl}_{3}\right)$ and chromic oxide $\left(\mathrm{Cr}_{2} \mathrm{O}_{3}\right)$ [3-5] organic sources of $\mathrm{Cr}$ such as $\mathrm{Cr}$ picolinate, $\mathrm{Cr}$ propionate, $\mathrm{Cr}$ methionine, and $\mathrm{Cr}$ acetate $(\mathrm{CrAc})$ have been widely researched in both humans and in various livestock species. Chromium propionate is the only dietary $\mathrm{Cr}$ source approved by the Food and Drug Administration (FDA) for use in ruminants in the U.S [6]. It can be included in the diet at a maximum dose of $0.5 \mathrm{mg} / \mathrm{kg}$ of diet dry matter (DM) for cattle, $0.2 \mathrm{mg} / \mathrm{kg}$ of 
diet DM for poultry, and $0.2 \mathrm{mg} / \mathrm{kg}$ of diet DM for swine [7]. Because Cr interacts with insulin receptors, it is highly involved in lipid and protein metabolism, glucose oxidation, gluconeogenesis, and fatty acid synthesis [2,8-10].

As reported by numerous studies in the previous 60 years, Cr supplementation is related to improved carbohydrate metabolism in both humans and animals. The $\mathrm{Cr}$ has been shown to improve insulin signaling and subsequently induce glucose and amino acid uptake in insulin sensitive tissues such as skeletal muscle and adipose tissue [11]. Intake of $\mathrm{Cr}$ increased glucose uptake by enhancing insulin responsiveness through various signaling pathways $[8,12]$. The impact of $\mathrm{Cr}$ source on adenosine monophosphate-activated protein kinase (AMPK) activity has also been reported in vitro and in vivo [12]. Variation of phosphorylated-AMPKa in muscle and adipose tissue can trigger metabolic changes that switch the cell from metabolic processes geared toward energy storage to energy consuming pathways [13]. The effect of $\mathrm{Cr}$ and alteration of body composition is variable across animal species. In swine, many have reported that feeding $\mathrm{Cr}$ increases the percentage of lean tissue but decreases percentage of fat accumulation [14]. Tokach et al [15] reported that Cr propionate upregulated adipogenic gene expression and resulted in enhancing adipogenic differentiation in bovine intramuscular (IM) adipocytes. It has also been reported that $\mathrm{Cr}$ supplementation in lactating Holstein dairy cows increased the net synthesis of fatty acids in various adipose tissue depot [16]. Therefore, we hypothesized that Cr may differentially regulate the AMPK signaling pathway in IM and subcutaneous (SC) adipocytes resulting in increased lipid accumulation between the two different adipose tissue depots.

\section{MATERIALS AND METHODS}

\section{Bovine preadipocyte isolation}

Bovine IM and SC adipose tissue were collected from between the 10th and 13th rib of longissimus dorsi (LD) muscle from four 16-mo old crossbred steers (predominantly Angus, 474.5 $\pm 50.2 \mathrm{~kg}$ ) following the method previously described [15]. The LD muscle was transported to the Texas Tech University Meat Science and Muscle Biology laboratory in phosphatebuffered saline (PBS: 0.76 M NaCl, 0.3 $\mathrm{M} \mathrm{NaH}_{2} \mathrm{PO}_{4}, \mathrm{pH}$ 7.2) that contained $3 \times$ antibiotic-antimycotic. The IM and SC tissues were then finely minced and incubated in Dulbecco's modified Eagle's medium (DMEM, Gibco, Waltham, MA, USA) with 5\% fetal bovine serum (FBS, Thermo Fisher Scientific, Waltham, MA, USA), collagenase (Sigma Aldrich, St. Louis, MO, USA), and $1 \times$ antibiotic-antimycotic (Gibco, USA) for 40 minutes. Digested adipose tissues were then filtered through a $250-\mu \mathrm{m}$ filter, and the suspension centrifuged at $2,000 \times \mathrm{g}$. After discarding the supernatant and lipid layer, the pellet was then washed three-times using DMEM. The pellet was then re-suspended and incubated in growth media composed of DMEM, 10\% FBS and $1 \times$ antibiotic-antimycotic at $37^{\circ} \mathrm{C}$ under a humidified atmosphere of $95 \% \mathrm{O}_{2}$ and $5 \% \mathrm{CO}_{2}$.

\section{Bovine preadipocyte cultures}

Bovine IM and SC preadipocytes were cultured in DMEM containing $10 \%$ FBS until reaching $~ 70 \%$ to $80 \%$ confluency. Differentiation media contained 5\% FBS, insulin $(10 \mu \mathrm{g} / \mathrm{mL})$, dexamethasone $(1 \mu \mathrm{M})$, ciglitizone $(10 \mu \mathrm{M})$, and oleic acid $(100 \mu \mathrm{M})$ and was used to induce differentiation of both IM and SC cells [15]. At the same time, different doses of $\mathrm{Cr}, 0$ (differentiation media only; CON), $0.1,1.0$, and $10.0 \mu \mathrm{M}$ as chromium acetate (CrAc; Sigma Aldrich, USA) were added to the differentiation media. After $96 \mathrm{~h}$ of incubation, cells were harvested to analyze gene expression and protein levels.

\section{Morphological analysis}

Oil-red-O (ORO) and hematoxylin staining were both used to determine the accumulation of lipid droplets. Cells were fixed with $10 \%$ neutral buffer formalin. After cells were rinsed with distilled water, fixed cells were then stained with $0.5 \%$ ORO solution (Sigma Aldrich, USA) in the dark for $20 \mathrm{~min}$, then washed with $60 \%$ propylene glycol (Sigma Aldrich, USA). Harris' hematoxylin (Sigma Aldrich, USA) was used to stain for nuclei in the dark for $3 \mathrm{~min}$. Cells were then coated with glycerol and kept in the dark until the imaging analyses. The IM and SC preadipocytes were identified by the presence of lipid droplets contained in the cytosol, which were changed to a red color via ORO staining. All cells were viewed with a Nikon Eclipse Ti-U microscope (Nikon Instruments; NY, USA). Images were processed using NIS-Elements software (Nikon Instruments, USA). Images were analyzed using Image J program (National Institutes of Health, Bethesda, MD, USA).

\section{Fluorescence microscopy}

Cells were grown on 3-well chamber microscopy glass slides (Cat. \#: 80381, Ibidi, Fitchburg, WI, USA). Slides were fixed with $4 \%$ paraformaldehyde (Thermo Fisher Scientific, USA) for $10 \mathrm{~min}$ at room temperature. In order to prevent nonspecific background staining, fixed cells were incubated in $1 \%$ bovine serum albumin for $30 \mathrm{~min}$. BODIPY (493/503, Thermo Fisher Scientific, USA) and BODIPY (558/568) phalloidin (Thermo Fisher Scientific, USA) diluted in dimethyl sulfoxide (Sigma-Aldrich, USA) at concentration of $1 \mathrm{mg} / \mathrm{mL}$ was used to stain neutral fat and F-actin respectively. Cells were then rinsed three times using PBS for $5 \mathrm{~min}$ at room temperature. In order to stain for nuclei, cells were stained with 4,6-diamidino-2-phenylindole (Thermo Fisher Scientific, USA) for $5 \mathrm{~min}$ and then washed twice with PBS. The slides were imaged at a magnification of $200 \times$ using an inverted fluorescence microscope (Nikon Eclipse, Ti-E; Nikon 
Instruments Inc., USA) equipped with a UV light source (Nikon Intensilight Inc., USA). All images were analyzed by the NIS Elements imaging software.

\section{Ribonucleic acid isolation}

Cultured preadipocytes were isolated using TRI reagent (SigmaAldrich, USA). The concentration and purity of RNA was determined with a spectrophotometer at an absorbance of $260 \mathrm{~nm}$ and $280 \mathrm{~nm}$ using a NanoDrop 1000 (NanoDrop products, Wilmington, DE, USA). An acceptable range of 1.76 to 2.05 was used for the 260:280 ratio. Ribonucleic acid $(1 \mu \mathrm{g})$ was then reverse transcribed via TaqMan Reverse Transcription reagents and MultiScribe Reverse Transcriptase (Applied Biosystems, Foster City, CA, USA) according to manufacturer recommendations. The primers used for $\mathrm{CDNA}$ synthesis were random hexamers.

\section{Gene expression}

Real-time quantitative polymerase chain reaction $(7900 \mathrm{HT}$ Real-Time PCR System, Applied Biosystems, USA) was used to measure the quantity of adenosine monophosphate-activated protein kinase a $(A M P K \alpha)$, glucose transporter 4 (GLUT4), G protein-coupled receptors 41 (GPR41), GPR43, peroxisome proliferator-activated receptor $\gamma(P P A R \gamma)$, and stearoyl-CoA desaturase $(S C D)$ relative to the quantity of ribosomal protein subunit 9 (RPS9) mRNA in total RNA (Table 1). Expression of RPS9 was not different across bovine tissue samples and used as a housekeeping gene $[17,18]$. Therefore, RPS9 was used as the endogenous control in order to normalize the expression of genes. Measurement of the relative quantity of the cDNA of interest was carried out using TAMRA PCR Master Mix (Applied Biosystems, USA) appropriate forward and reverse primers, and cDNA mixture. Assays were performed in triplicate determinations using and the thermal cycling parameters recommended by the manufacturer ( 40 cycles of $15 \mathrm{~s}$ at $95^{\circ} \mathrm{C}$ and $1 \mathrm{~min}$ at $60^{\circ} \mathrm{C}$ ). Titration of mRNA primers against increasing amounts of cDNA yielded linear responses with slopes between -2.8 and -3.0. Real-time quantitative (RQ) values based on $\Delta \Delta \mathrm{CT}^{-2}$ were analyzed by RQ manager (Applied Biosysytems, USA).

\section{Western blotting}

Cultured preadipocytes were isolated using ice-cold M-PER (Thermo Fisher Scientific, USA), protease inhibitor (SigmaAldrich, USA), and $2 \mathrm{mM} \mathrm{Na}_{3} \mathrm{VO}_{4}$ (Thermo Fisher Scientific, USA). Homogenated cells were then mixed with an equal volume of $2 \times$ standard sodium dodecyl sulfate (SDS) sample loading buffer (Invitrogen, Waltham, MA, USA). Gradient gels were used for SDS-polyacrylamide gel electrophoresis separation of proteins. Membranes were then incubated overnight at $4^{\circ} \mathrm{C}$ in primary antibodies: anti-AMPKa, rabbit polyclonal (Cell signaling, Danvers, MA, USA) with dilution
Table 1. Primer and probe sequences for the gene expression analysis

\begin{tabular}{|c|c|}
\hline Genes & Sequence $\left(5^{\prime}\right.$ to $\left.3^{\prime}\right)$ \\
\hline \multicolumn{2}{|l|}{ AMPKa } \\
\hline Forward & ACCATTCTTGGTTGCTGAAACTC \\
\hline Reverse & CACCTTGGTGTTTGGATTTCTG \\
\hline TaqMan probe & 6FAM-CAGGGCGCGCCATACCCTTG-TAMRA \\
\hline \multicolumn{2}{|l|}{$C E B P \beta$} \\
\hline Forward & CCAGAAGAAGGTGGAGCAACTG \\
\hline Reverse & TCGGGCAGCGTCTTGAAC \\
\hline TaqMan probe & 6FAM-CGCGAGGTCAGCACCCTGC-TAMRA \\
\hline \multicolumn{2}{|l|}{ GPR41 } \\
\hline Forward & TGCTCCTCAGCACCCTGAA \\
\hline Reverse & TTGGAACCCAGATGATGAGAAA \\
\hline TaqMan probe & 6FAM-TCCTGCGTCGACCCCCTTGTCTAC-TAMRA \\
\hline \multicolumn{2}{|l|}{ GPR43 } \\
\hline Forward & GGCTTTCCCCGTGCAGTA \\
\hline Reverse & ATCAGAGCAGCCATCACTCCAT \\
\hline TaqMan probe & 6FAM-AAGCTGTCCCGCCGGCCC-TAMRA \\
\hline \multicolumn{2}{|l|}{ PPAR $\gamma$} \\
\hline Forward & ATCTGCTGCAAGCCTTGGA \\
\hline Reverse & TGGAGCAGCTTGGCAAAGA \\
\hline TaqMan probe & 6FAM-CTGAACCACCCCGAGTCCTCCCAG-TAMRA \\
\hline \multicolumn{2}{|r|}{ 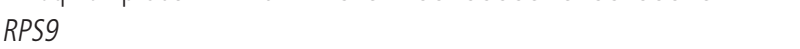 } \\
\hline Forward & GAGCTGGGTTTGTCGCAAAA \\
\hline Reverse & GGTCGAGGCGGGACTTCT \\
\hline TaqMan probe & 6FAM-ATGTGACCCCGCGGAGACCCTTC-TAMRA \\
\hline \multicolumn{2}{|l|}{$S C D$} \\
\hline Forward & TGCCCACCACAAGTTTTCAG \\
\hline Reverse & GCCAACCCACGTGAGAGAAG \\
\hline TaqMan probe & 6FAM-CCGACCCCCACAATTCCCG-TAMRA \\
\hline
\end{tabular}

AMPKa, adenosine monophosphate-activated protein kinase- $\alpha$; C/EBP $\beta$, CCAAT/ enhancer-binding protein $\beta ;$ GPR41, G protein couple receptor 41; PPAR $\gamma$, peroxisome proliferated activate receptor $\gamma ; R P S 9$, ribosomal protein subunit $9 ; S C D$, stearoyl CoA desaturase.

of 1:1,000, anti-phosphorylated AMPKa, rabbit polyclonal (Cell signaling, USA) with dilution of 1:1,000. Membranes were then incubated with a secondary antibody, Alexa-Fluor 633, goat anti-rabbit, dilution at 1:2,000 dilution for $2 \mathrm{~h}$ at the room temperature. After three 10 min washes, membranes were visualized using enhanced chemiluminescent substrate, Western blotting reagents (Thermo Fisher Scientific, USA), and exposure to film (MR, Kodak, Rochester, NY, USA). Density of the bands were quantified using Imager Scanner II and Image Quant TL software. To reduce the variation between blots, tissue lysates of both groups were run in a single gel. Band density was normalized according to the glyceraldehyde 3-phosphate dehydrogenase (Cell signaling, USA) content within each sample.

\section{Statistical analysis}

Data were analyzed as completely randomized design via the Mixed procedure of SAS 9.4 (SAS Institute Inc., Cary, NC, USA). Each level of CrAc was replicated 6 times. When a 
significant preliminary F-test was detected, CrAc doses were separated and denoted to be different via the pairwise comparisons option of SAS. All results are reported as least-squares means. An a level of 0.05 was used to determine significance, with tendencies discussed at p-values between 0.05 and 0.10 .

\section{RESULTS}

\section{Morphological changes}

Morphological results indicated that CrAc treated adipocytes had a greater number of lipid droplets in IM and SC adipocytes compared to control (Figures 1 and 2). Bovine preadipocytes treated with CrAc contained oil-red O staining of the triacylglycerol in both IM and SC adipocytes (Figure 1). Multilocular lipid droplets developed in the cultured IM adipocytes, but unilocular lipid droplets accumulated in the SC adipocytes after 96 hours of differentiation. Lipid droplets and cell structures were visualized using BODIPY staining in IM and SC (Figure 2). Both IM and SC tended to accumulate more lipid droplets when they were incubated with CrAc $(10 \mu \mathrm{M})$ compared to the control.

Effects of chromium acetate on gene expression intramuscular adipocytes

High concentration $(10 \mu \mathrm{M})$ of CrAc treatment increased (p $=0.02) \mathrm{C} / E B P \beta$, an early adipogenic transcription factor, mRNA concentration in IM adipocyte cell cultures (Figure 3). Relative mRNA expression of another key transcription factor for adipogenesis, $P P A R \gamma$, was also upregulated $(\mathrm{p}=0.03)$ when $10 \mu \mathrm{M}$ of $\mathrm{CrAc}$ was included in the differentiation media compared to CON. Additionally, relative mRNA expression of the late adipogenic transcription factor, $S C D$, increased ( $\mathrm{p}$ $=0.04$ ) when $10 \mu \mathrm{M}$ of CrAc was included in the differentiation media. The inclusion of CrAc in IM adipocyte cell cultures did not alter ( $\mathrm{p}>0.05)$ mRNA abundance of AMPK $\alpha$, GLUT4, GPR41, or GPR43.

\section{Effects of chromium acetate on gene expression -} subcutaneous adipocytes

In bovine SC adipocyte cell cultures, the inclusion of $10 \mu \mathrm{M}$ $\mathrm{CrAc}$ in the differentiation cocktail resulted in the downregulation ( $\mathrm{p}<0.02$ ) of $A M P K \alpha$ expression compared to $0.1 \mu \mathrm{M}$ and $1 \mu \mathrm{M}$ of CrAc (Figure 4). However, there was no difference ( $p>0.05)$ detected between $\mathrm{CON}$ and $10 \mu \mathrm{M}$ CrAc for mRNA expression of $A M P K \alpha$. The inclusion of CrAc increased $(\mathrm{p}=0.02) C / E B P \beta$ mRNA abundance at the concentrations of $1 \mu \mathrm{M}$ and $10 \mu \mathrm{M}$. Expression of $S C D$ also significantly increased $(p<0.01)$ when SC adipocyte cells were cultured with $10 \mu \mathrm{M}$ of CrAc. Addition of CrAc did not affect gene expression of GLUT4. Chromium acetate also did not alter the gene expression of GPR41 and GPR43 in SC adipocytes.

\section{Phosphorylated-AMPKa and AMPKa protein level} Western blotting was used to measure the ratio of phosphorylated-AMPKa to AMPKa (Figure 5). The ratio of phosphorylated-AMPKa to AMPKa was decreased $(p<0.01)$

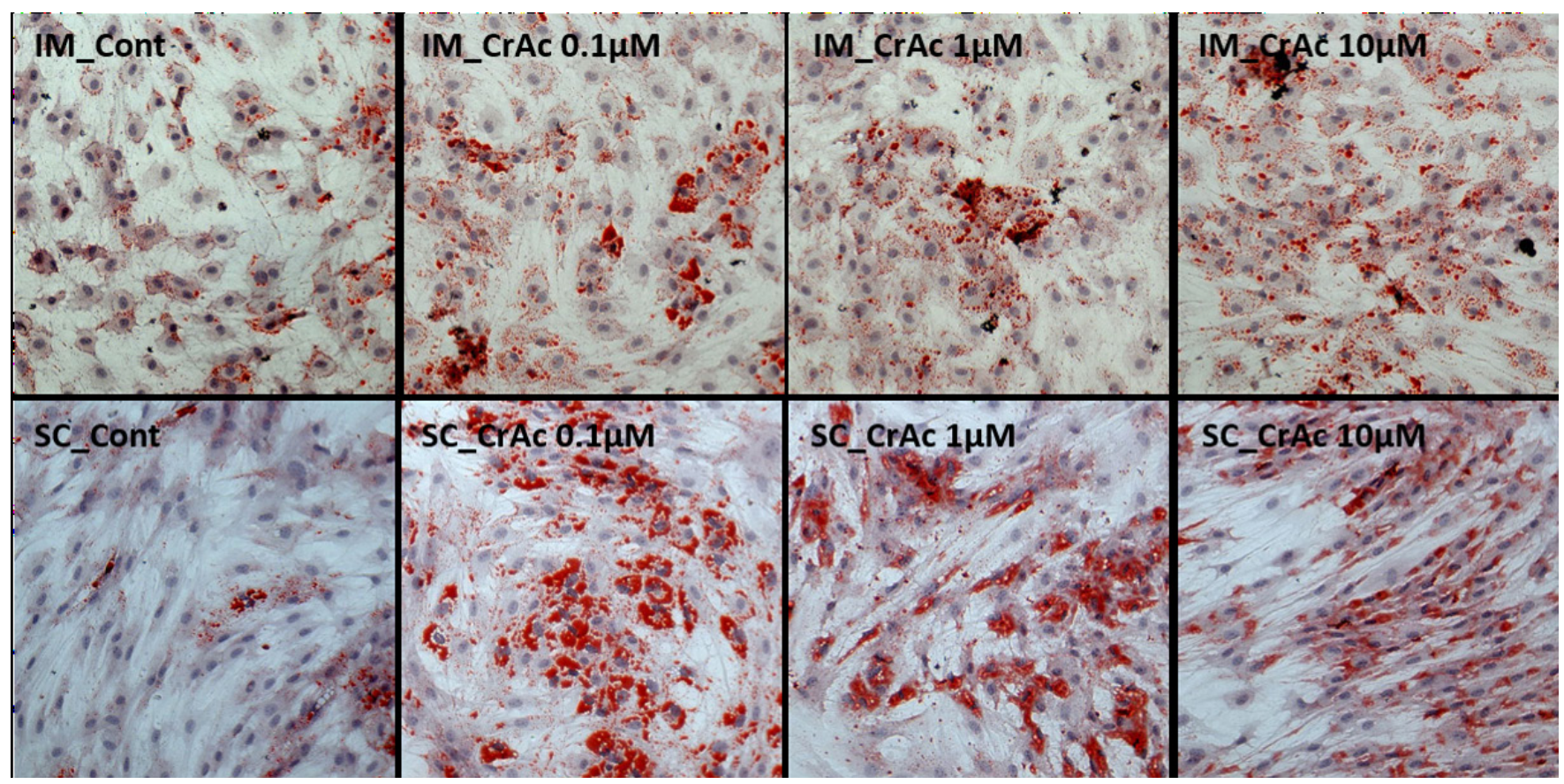

Figure 1. Lipid droplet visualization using oil-red-0 staining. Bovine intramuscular (IM) and subcutaneous (SC) adipocytes were stained $96 \mathrm{~h}$ after differentiation. Cytoplasmic lipids were stained with oil-red 0 (red). Nuclei were stained with hematoxylin (blue). Stained cells were imaged at a magnification of 200x. 
A
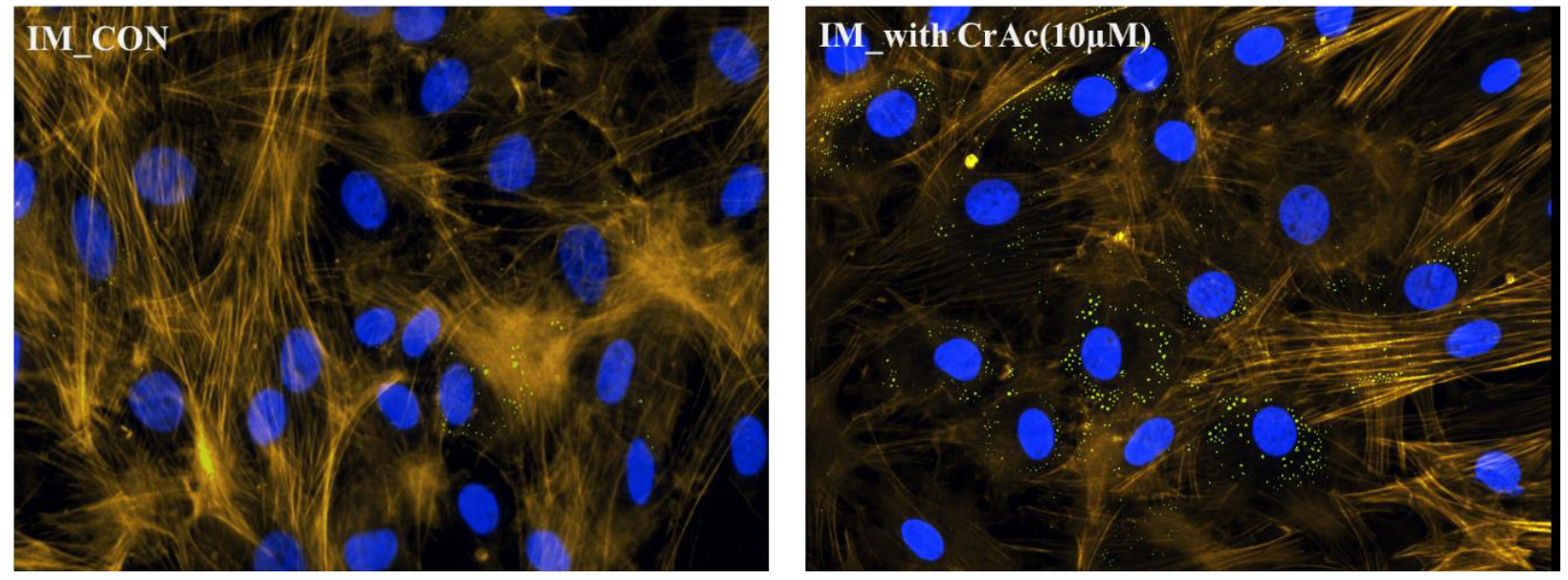

B
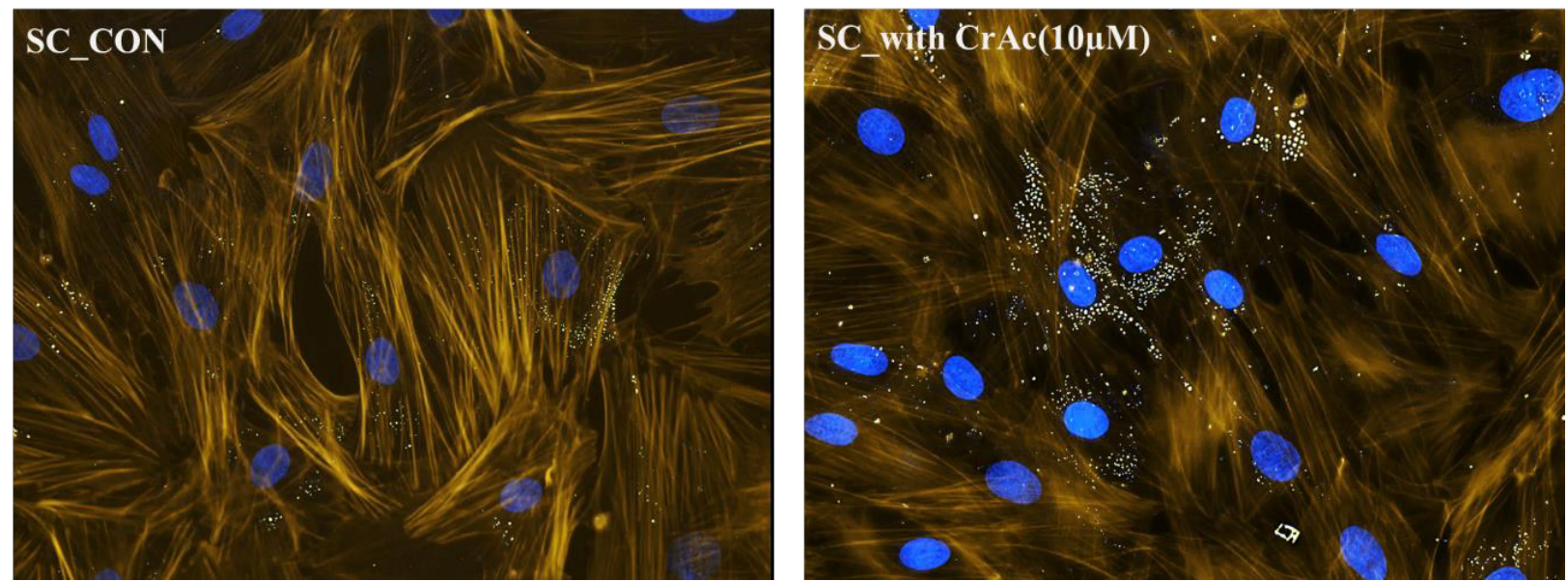

Figure 2. Visualization of lipid droplets in bovine intramuscular (IM) (A); and subcutaneous (SC) (B) adipose cells. Bovine IM and SC adipocytes were fixed $96 \mathrm{~h}$ after inducing differentiation. Lipid droplets were stained with BODIPY 493/503 (green). 4',6-diamidino-2-phenylindole (DAPI) were used for staining nuclei (blue). F-actin was labelled with Bodipy 558/568 phalloidin (yellow). Stained cells were imaged at a magnification of 200x.

$50 \%$ when bovine IM adipocytes were exposed to $0.1,1$, and $10 \mu \mathrm{M}$ of CrAc. However, CrAc inclusion did not alter ( $\mathrm{p}=$ 0.74 ) the ratio of phosphorylated-AMPKa to AMPKa in bovine SC adipocytes.

\section{Effects of acetate on adipose cells}

To ensure the treatment effects are due to the addition of chromium source, rather than acetate, sodium acetate $(\mathrm{NaAc})$ was treated on both bovine IM and SC adipocytes. Incubation with $10 \mu \mathrm{M}$ of NaAc did not alter $(\mathrm{p}<0.05) \mathrm{AMPKa}, \mathrm{C} / \mathrm{EBP} \beta, \mathrm{SCD}$, PPAR $\gamma$, GLUT4, and GPR43 relative mRNA abundance in IM or SC adipocyte cell cultures (Figure 6).

\section{DISCUSSION}

Chromium plays an important role in mammals as an essential nutrient due to its substantial roles in the metabolism of various nutrients [16], insulin and glucagon regulation $[9,19]$, and the immune system [20]. From the livestock animal standpoint, supplementation of $\mathrm{Cr}$ sources can influence live performance in cattle [21], and alter body composition in swine [14]. Chromium is well known to improve glucose metabolism through the enhancement of insulin sensitivity; primarily through improvement of insulin binding to its receptor, proliferation of insulin receptors, and activation of the intracellular tyrosine kinase domains contained within the insulin receptor [22]. Insulin triggers the downstream signaling pathway through phosphorylation of insulin receptor substrate 1 and phosphoinositide 3-kinases [23]. Ultimately, this results in enhancement of glucose uptake in insulin sensitive tissues by regulating the translocation of GLUT4 from the cytoplasm to the cell membrane in insulin-sensitive tissues. Tokach et al [15] reported that chromium propionate effectively increased mRNA expression of GLUT4 during 
AMPK $\alpha$

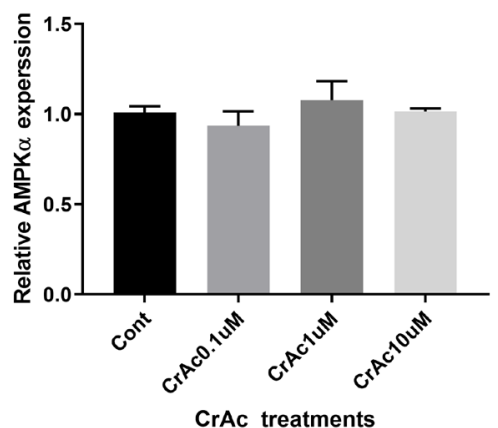

GLUT4

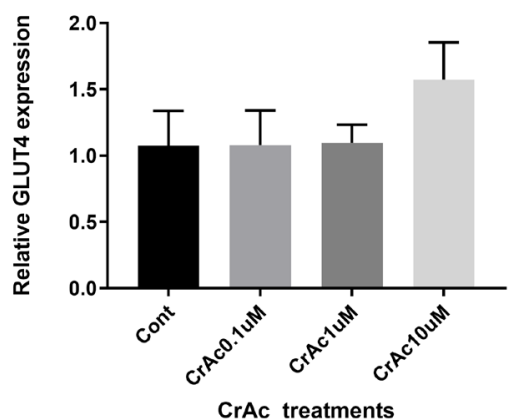

GPR43

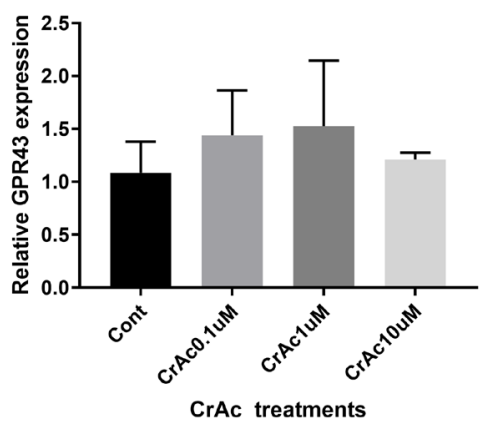

SCD

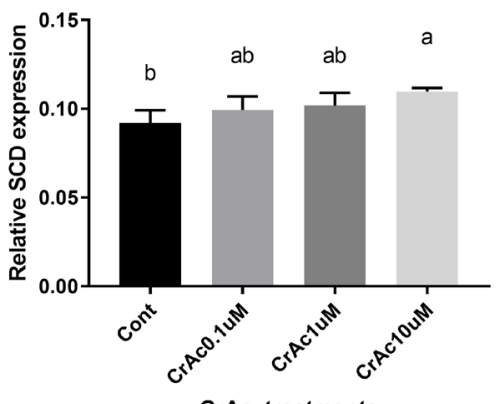

CEBP $\beta$

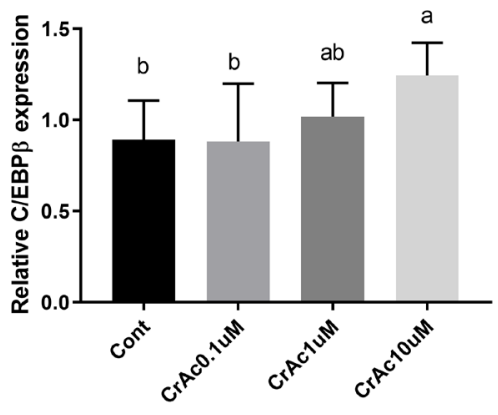

CrAc treatments

GPR41

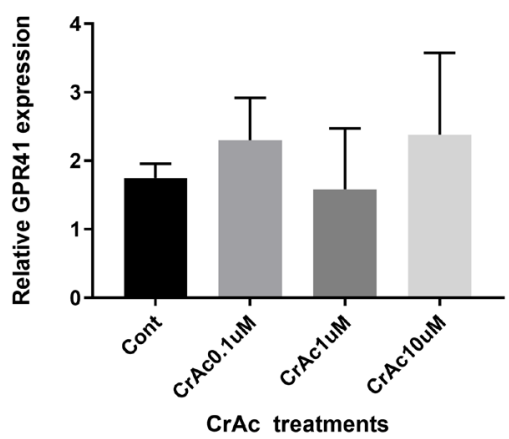

PPAR $\gamma$

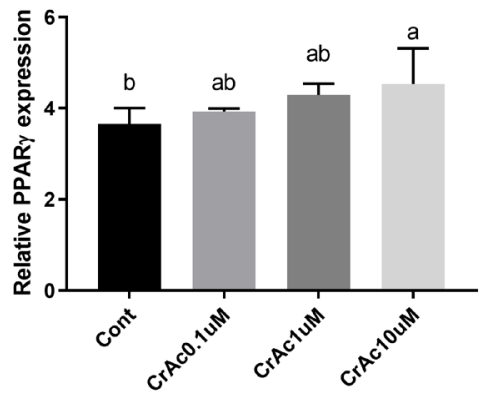

CrAc treatments

CrAc treatments

Figure 3. Gene expression associated with adipogenic differentiation in bovine intramuscular adipocytes (IM). Quantity of AMPK $\alpha$, C/EBP $\beta$, PPAR $\gamma$, GPR41, GPR43, and SCD mRNA relative to that of ribosomal protein subunit 9 (RPS9) mRNA in total RNA isolated from cultured bovine intramuscular adipocytes were analyzed by real timepolymerase chain reaction. Addition of chromium increased $(p<0.05)$ mRNA concentration of key transcription factors during adipogenesis, C/EBP $\beta$, PPAR $\gamma$. Expression of SCD also upregulated $(p<0.01)$ by chromium acetate $(\mathrm{CrAc})$ treatment. AMPKa, adenosine monophosphate-activated protein kinase- $\alpha$; C/EBP $\beta$, CCAAT/enhancer-binding protein $\beta$; PPAR $\gamma$, peroxisome proliferated activate receptor $\gamma$; GPR41, G protein couple receptor 41; SCD, stearoyl CoA desaturase.

differentiation of bovine IM adipocytes compared to bovine SC adipocyte. In addition, chromium $\left(\mathrm{Cr}^{3+}\right)$ improved the GLUT4 translocation in 3T3-L1 adipocytes [24].
In the ruminant animal, it has been proposed that glucose is the primary substrate for adipogenesis in IM adipocytes, while SC adipocytes prefer to utilize the volatile fatty acid, 
AMPK $\alpha$

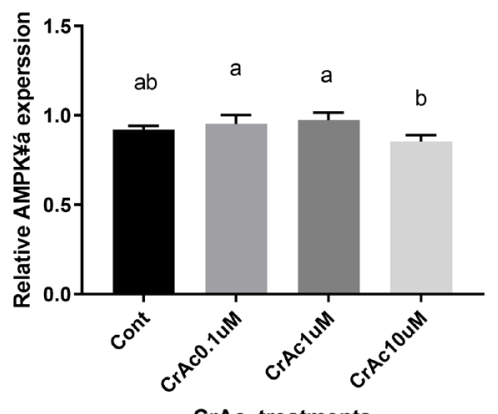

GLUT4

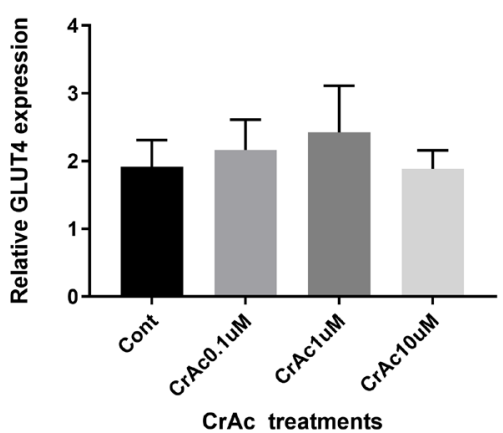

GPR43

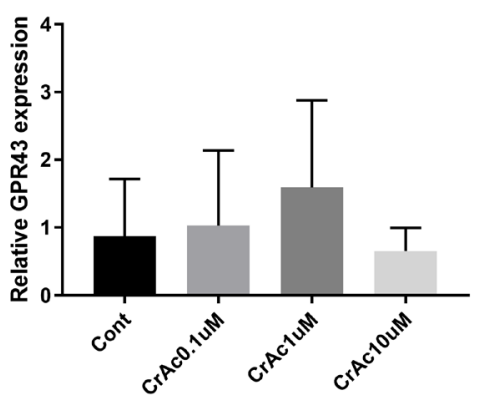

CrAc treatments

SCD

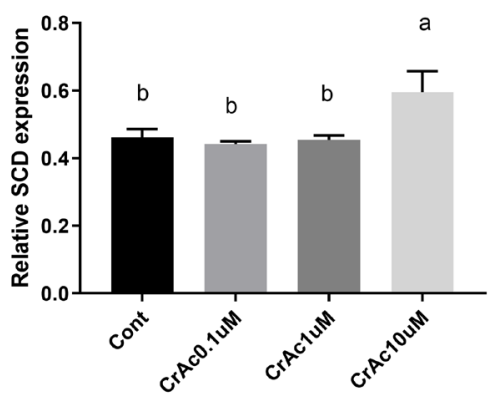

CrAc treatments
CEBPB

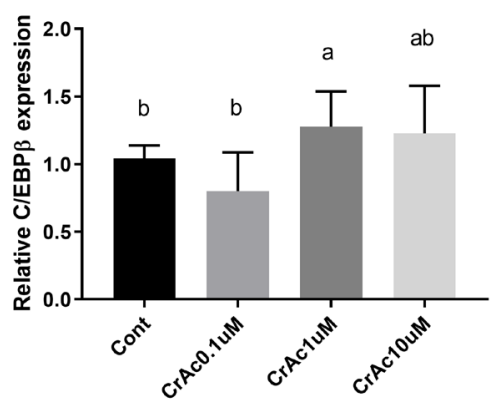

CrAc treatments

GPR41

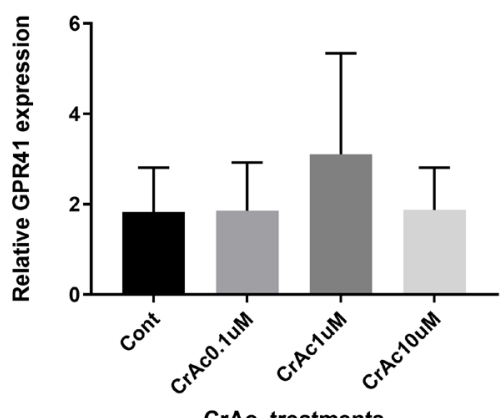

PPAR $\gamma$

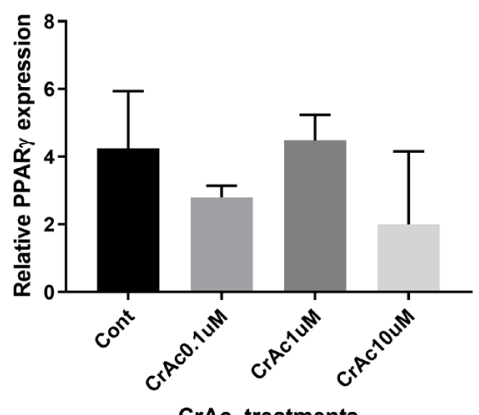

Figure 4. Gene expression associated with adipogenic differentiation in bovine subcutaneous adipocytes (SC). Quantity of AMPKa, C/EBP $\beta$, PPAR $\gamma$, GPR41, GPR43, and SCD mRNA relative to that of ribosomal protein subunit 9 (RPS9) mRNA in total RNA isolated from cultured bovine intramuscular adipocytes were analyzed by real timepolymerase chain reaction. Addition of chromium increased $(p<0.05)$ mRNA concentration of the early transcription factor during adipogenesis, $C / E B P \beta$. Expression of $S C D$ also upregulated $(p<0.01)$ by chromium acetate $(\mathrm{CrAc})$ treatment.

acetate, produced via ruminal fermentation, as the primary precursor for lipid synthesis [25]. Preferential substrates differ for lipogenesis between various adipose tissue depots, and
CrAc could differentially impact the lipid filling in various adipose tissue depots. Chromium markedly improves glucose uptake into insulin sensitive tissues such as adipose tissue and 
(A)

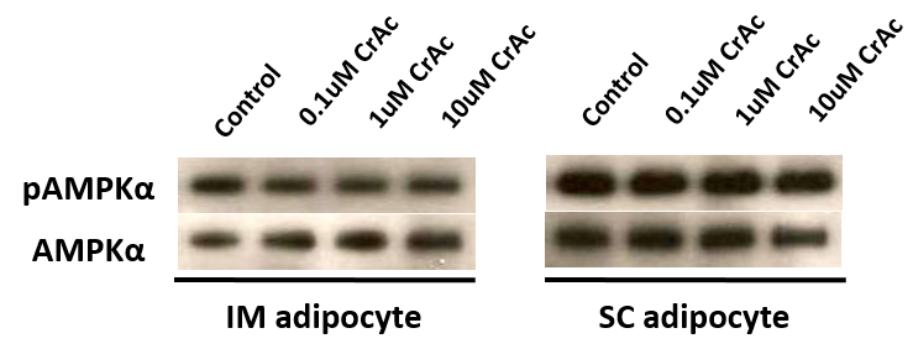

(B)

IM

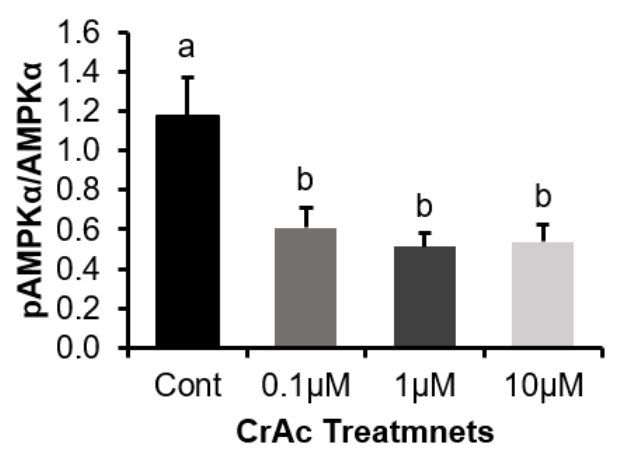

SC

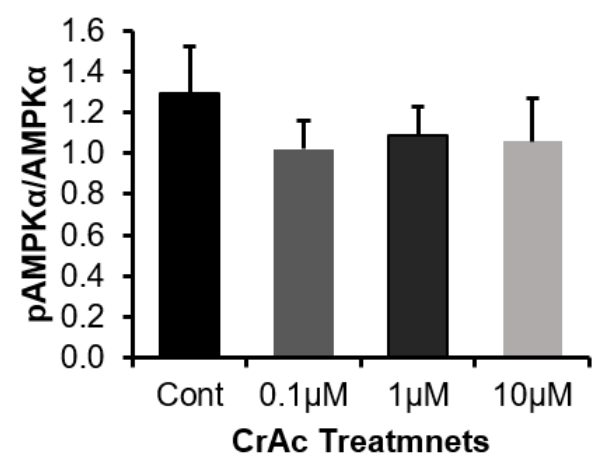

Figure 5. (A) Protein ration of phosphorylated AMPKa (PAMPK) to AMPKa. (B) The ratio of pAMPKa to AMPKa protein expression of bovine intramuscular and subcutaneous adipocytes are shown as determined by the western blotting technique. AMPKa, adenosine monophosphate-activated protein kinase-a.

(A)

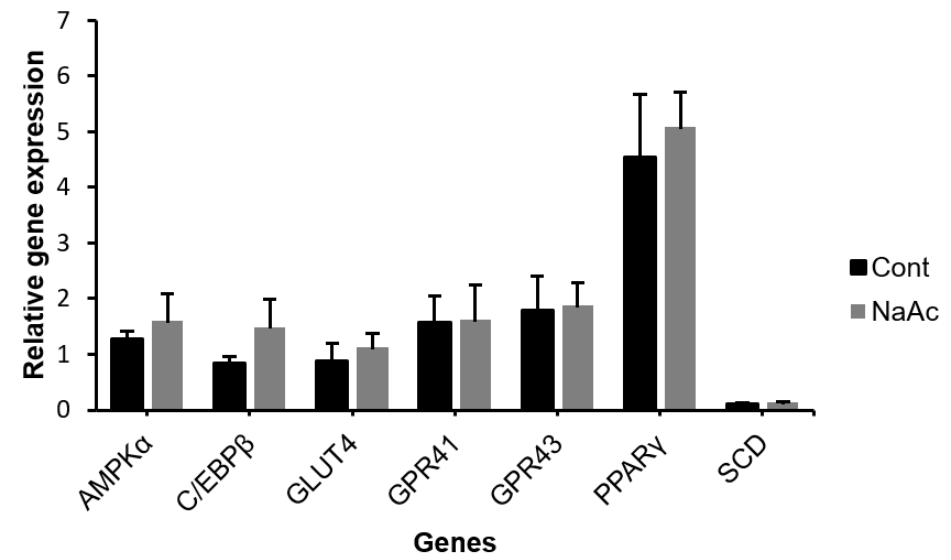

(B)

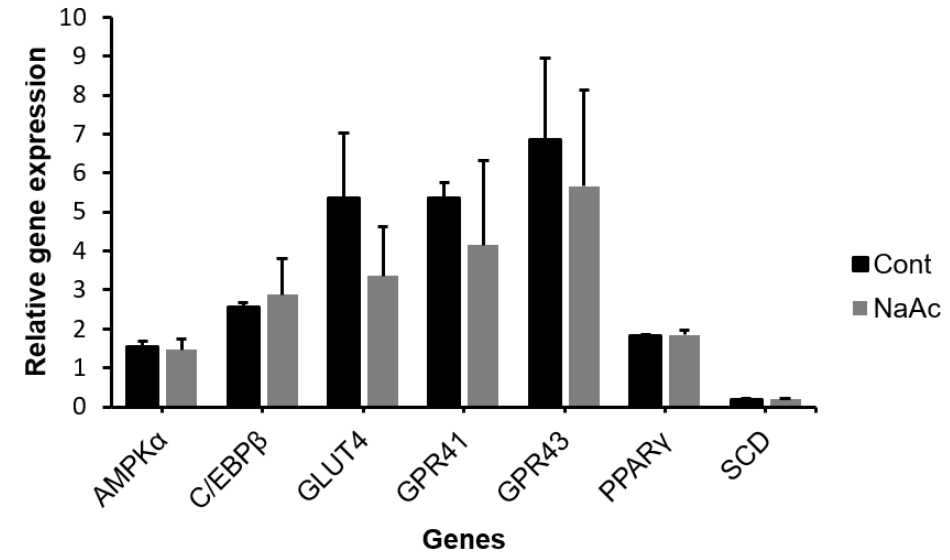

Figure 6. The effect of sodium acetate (NaAc) on cultured bovine intramuscular (IM) (A); and subcutaneous (SC) (B) adipocytes. Sodium acetate was added with the differentiation media to investigate the effect of acetate. After $96 \mathrm{~h}$ of incubation adipocytes were harvested for gene expression analysis. No significant different was found across genes $(p>0.05)$. 
muscle [15]. Therefore, increasing the availability of glucose for uptake of IM adipose cells via GLUT4 can increase the accumulation of triglycerides within the IM adipocyte, but not SC adipocytes. This could explain why $\mathrm{Cr}$ decreases SC fat accumulation in pigs [14]. In the present study, the addition of CrAc in the differentiation media did not alter the GLUT4 gene expression in either IM or SC adipocytes. Since only the relative mRNA expression of GLUT4 was measured, there was no way of elucidating whether or not the GLUT4 measured was contained in the cytosol or was membrane bound. The potential exists that the amount of GLUT4 that existed in cytoplasm of the adipocytes remains constant, but translocation of GLUT4 may occur when adipocytes are exposed to $\mathrm{Cr}$ sources.

Various studies have reported that the addition of $\mathrm{Cr}$ to livestock diets can have a positive effect on weight gain and variable effects on body composition [17]. A positive impact on weight seems more prominent when animals are exposed to stressful circumstances such as weaning, or co-mingling with foreign sources of cattle during marketing, and transportation [26]. In cattle, $\mathrm{Cr}$ has not been shown to alter body composition; however, it can decrease SC fat accumulation without altering longissimus muscle area [23]. Another study using bovine IM preadipocytes noted that addition of $\mathrm{Cr}$ propionate increased expression of PPAR $\gamma$, a key adipogenic transcription factor that may result in a compositional tissue change [15].

The induction of adipocyte differentiation involves the interplay of members of the C/EBP and PPAR families of transcription factors [27]. There are two dominant C/EBP isoforms during adipogenesis: $\mathrm{C} / \mathrm{EBP} \alpha$ and $\mathrm{C} / \mathrm{EBP} \beta$. Expression of $\mathrm{C} / \mathrm{EBP} \beta$ in preadipocytes is initially low but greatly increases during the early stage of terminal differentiation [28]. Expression of C/EBP $\beta$ induces the activity of indispensable transcription factor, PPAR $\gamma$. The PPAR $\gamma$ plays a critical role during adipogenic differentiation and simultaneously controls lipid metabolism-related gene expression. In lipid and glucose metabolism, synthetic PPAR $\gamma$ ligands including troglitazone, rosiglitazone, and pioglitazone, stimulate glucose uptake and increased insulin sensitivity in adipocytes, hepatocytes, and skeletal muscle cells $[29,30]$. Our data indicated that the expression of $C / E B P \beta$ mRNA was upregulated when SC adipocytes were exposed to 1 and $10 \mu \mathrm{M}$ of $\mathrm{CrAc}$ in the differentiation media. The IM adipocytes also increased expression of $C / E B P \beta$ when $10 \mu \mathrm{M}$ of $\mathrm{CrAc}$ was included in the differentiation media. The PPAR $\gamma$, was highly expressed in IM when $10 \mu \mathrm{M}$ of $\mathrm{CrAc}$ was added. However, the inclusion of any level of CrAc in the differentiation media of SC adipocytes did not alter PPARy expression relative to CON. Therefore, $\mathrm{Cr}$ source may only promote the accumulation of marbling fat via stimulating key transcription factors, $C / E B P \beta$ and PPAR $\gamma$. The varied responses from CrAc might be be- cause biological and physiological differences exist between IM and SC adipose cells [31]. Recent findings reported that the IM and intermuscular adipose cells may be derived from myogenic lineage, not from adipogenic progenitors. While the overall pattern of expression of transcription factors, including C/EBP $\beta$ and PPAR $\gamma$, seems to be not much different between IM and SC adipose cells [32]. The SCD is closely associated with adipogenesis and composition of muscle monounsaturated fatty acids [33]. The greatest concentration $(10 \mu \mathrm{M})$ of CrAc increased SCD mRNA abundance in both IM and SC adipocyte cell cultures.

It is well known that AMPK plays significant role in cellular energy homeostasis. The activity of AMPK is regulated by various factors, such as the AMP:ATP ratio, exercise [34], and various hormones or cytokines [35]. The stimulatory role of AMPK in glucose transportation has been suggested, but there are a limited number of studies that have addressed the role of AMPK in glucose uptake in adipose cells [36]. Studies using mature adipocytes have reported that the activation of AMPK enhanced basal glucose uptake [37]. However, Salt et al [38] has shown that activation of AMPK did not affect the glucose uptake. The role of AMPK during adipogenic differentiation and lipid metabolism in adipose cells is better understood. During differentiation of preadipocytes, AMPK downregulates many key transcription factors involved in adipogenesis. Dagon et al [39] reported that the AMPK is associated with apoptosis, inhibition of lipolysis, and downregulation of the adipogenic transcription factors, PPAR $\gamma$ and $\mathrm{C} / \mathrm{EBPa}$ in the adipogenic induced 3T3-F442a fibroblast cell line. Another study conducted using 3T3-L1 adipocytes and 5-aminoimidazole- 4 -carboxamide-1- $\beta$-d-ribonucleoside, which activates AMPK, suppressed the expression of PPAR $\gamma$ [13].

The AMPK complex is activated by phosphorylation of Thr 172 position of the $\alpha$-subunit [40]. Merely measuring relative abundance of AMPK mRNA provided little insight into what is actually occurring in vivo. Thus, the ratio of phosphorylatedAMPK to AMPK must be measured. In the current study, the ratio of phosphorylated-AMPK to AMPK was decreased when CrAc was added to IM adipocytes; however, this did not occur in SC adipocytes. Conversely, chromium picolinate increased AMPK activity in L6 skeletal muscle cells [12].

Based on our findings, Cr sources likely stimulate adipogenesis both in IM and SC by stimulating key adipogenic transcription factors including $\mathrm{C} / \mathrm{EBP} \beta, \mathrm{PPAR} \gamma$, and SCD. Our data also indicated that CrAc may deactivate the phosphorylation of AMPK and increased adipose cell development in IM but not in SC.

\section{CONFLICT OF INTEREST}

We certify that there is no conflict of interest with any financial 
organization regarding the material discussed in the manuscript.

\section{ACKNOWLEDGMENTS}

This study supported in part by funding from the Gordon W. Davis Regents Chair in Meat Science and Muscle Biology Endowment at Texas Tech University.

\section{REFERENCES}

1. Barnhart J. Occurrences, uses, and properties of chromium. Regul Toxicol Pharmacol 1997;26:S3-S7. https://doi.org/10. 1006/rtph.1997.1132

2. Pechova A, Pavlata L. Chromium as an essential nutrient: a review. Vet Med (Praha) 2007;52:1.

3. Dowling HJ, Offenbacher EG, Pi-Sunyer FX. Absorption of inorganic, trivalent chromium from the vascularly perfused rat small intestine. J Nutr 1989;119:1138-45. https://doi.org/ 10.1093/jn/119.8.1138

4. Qiao W, Peng Z, Wang Z, Wei J, Zhou A. Chromium improves glucose uptake and metabolism through upregulating the mRNA levels of IR, GLUT4, GS, and UCP3 in skeletal muscle cells. Biol Trace Elem Res 2009;131:133-42. https://doi.org/ 10.1007/s12011-009-8357-2

5. Lien TF, Wu CP, Wang BJ, et al. Effect of supplemental levels of chromium picolinate on the growth performance, serum traits, carcass characteristics and lipid metabolism of growingfinishing pigs. Anim Sci 2001;72:289-96. https://doi.org/10. 1017/S1357729800055788

6. US Food and Drug Administration. CFR-code of federal regulations title 21 Part 556 tolerances for residues of new animal drugs in food. Rockville, MD, USA: US Food and Drug Administration; 2017.

7. Spears JW. Chromium supplementation in cattle diets. In: Florida Rumint Nutrion Symphosium, Gainesville, FL, USA; 2010. p. 143-55.

8. Mertz W. Chromium in human nutrition: a review. J Nutr 1993;123:626-33. https://doi.org/10.1093/jn/123.4.626

9. Anderson RA, Polansky MM, Bryden NA, Canary JJ. Supplemental-chromium effects on glucose, insulin, glucagon, and urinary chromium losses in subjects consuming controlled low-chromium diets. Am J Clin Nutr 1991;54:909-16. https:// doi.org/10.1093/ajcn/54.5.909

10. Mertz W. Chromium occurrence and function in biological systems. Physiol Rev 1969;49:163-239. https://doi.org/10. 1152/physrev.1969.49.2.163

11. Vincent JB. The biochemistry of chromium. J Nutr 2000;130: 715-8. https://doi.org/10.1093/jn/130.4.715

12. Hoffman NJ, Penque BA, Habegger KM, Sealls W, Tackett L, Elmendorf JS. Chromium enhances insulin responsiveness via AMPK. J Nutr Biochem 2014;25:565-72. https://doi.org/ 10.1016/j.jnutbio.2014.01.007

13.Tong JF, Yan X, Zhu MJ, Ford SP, Nathanielsz PW, Du M. Maternal obesity downregulates myogenesis and $\beta$-catenin signaling in fetal skeletal muscle. Am J Physiol Endocrinol Metab 2009;296:E917-E24. https://doi.org/10.1152/ajpendo. 90924.2008

14. Mooney K, Cromwell G. Effects of dietary chromium picolinate supplementation on growth, carcass characteristics, and accretion rates of carcass tissues in growing-finishing swine. J Anim Sci 1995;73:3351-7. https://doi.org/10.2527/1995.73113351x

15. Tokach RJ, Ribeiro FR, Chung KY, Rounds W, Johnson BJ. Chromium propionate enhances adipogenic differentiation of bovine intramuscular adipocytes. Front Vet Sci 2015;2:26. https://doi.org/10.3389/fvets.2015.00026

16. McNamara J, Valdez F. Adipose tissue metabolism and production responses to calcium propionate and chromium propionate. J Dairy Sci 2005;88:2498-507. https://doi.org/10. 3168/jds.S0022-0302(05)72927-1

17. Bionaz M, Loor JJ. Identification of reference genes for quantitative real-time PCR in the bovine mammary gland during the lactation cycle. Physiol Genomics 2007;29:312-9. https:// doi.org/10.1152/physiolgenomics.00223.2006

18. Janovick-Guretzky N, Dann H, Carlson D, Murphy M, Loor J, Drackley J. Housekeeping gene expression in bovine liver is affected by physiological state, feed intake, and dietary treatment. J Dairy Sci 2007;90:2246-52. https://doi.org/10.3168/ jds.2006-640

19.Spears JW, Whisnant CS, Huntington GB, et al. Chromium propionate enhances insulin sensitivity in growing cattle. J Dairy Sci 2012;95:2037-45. https://doi.org/10.3168/jds.20114845

20. Burton JL. Supplemental chromium: its benefits to the bovine immune system. Anim Feed Sci Technol 1995;53:117-33. https://doi.org/10.1016/0377-8401(95)02016-S

21. Bernhard BC, Burdick NC, Rounds W, et al. Chromium supplementation alters the performance and health of feedlot cattle during the receiving period and enhances their metabolic response to a lipopolysaccharide challenge. J Anim Sci 2012; 90:3879-88. https://doi.org/10.2527/jas.2011-4981

22. Anderson RA, Bryden NA, Evock-Clover CM, Steele NC. Beneficial effects of chromium on glucose and lipid variables in control and somatotropin-treated pigs are associated with increased tissue chromium and altered tissue copper, iron, and zinc. J Anim Sci 1997;75:657-61. https://doi.org/10.2527/ 1997.753657x

23. Kanai F, Ito K, Todaka M, et al. Insulin-stimulated GLUT4 translocation is relevant to the phosphorylation of IRS-1 and the activity of PI3 kinase. Biochem Biophys Res Commun 1993;195:762-8. https://doi.org/10.1006/bbrc.1993.2111

24.Chen G, Liu P, Pattar GR, et al. Chromium activates glucose transporter 4 trafficking and enhances insulin-stimulated glucose transport in 3T3-L1 adipocytes via a cholesterol- 
dependent mechanism. Mol Endocrinol 2006;20:857-70. https://doi.org/10.1210/me.2005-0255

25.Crouse JD, Smith SB, Prior RL. Bovine muscle glycogen as affected by fasting and refeeding. J Anim Sci 1984;59:384-7. https://doi.org/10.2527/jas1984.592384x

26. Moonsie-Shageer S, Mowat D. Effect of level of supplemental chromium on performance, serum constituents, and immune status of stressed feeder calves. J Anim Sci 1993;71:232-8. https://doi.org/10.2527/1993.711232x

27.Villarroya F, Giralt M, Iglesias R. Retinoids and adipose tissues: metabolism, cell differentiation and gene expression. Int J Obes 1999;23:1-6. https://doi.org/10.1038/sj.ijo.0800799

28.Symonds ME, editor. Adipose tissue biology. New York, NY, USA: Springer; 2012. https://doi.org/10.1007/978-3-31952031-5_1

29.Janani C, Kumari BDR. PPAR gamma gene-a review. Diabetes Metab Syndr Clin Res Rev 2015;9:46-50. https://doi.org/10. 1016/j.dsx.2014.09.015

30.van Raalte DH, Li M, Pritchard PH, Wasan KM. Peroxisome proliferator-activated receptor (PPAR)- $\alpha$ : a pharmacological target with a promising future. Pharm Res 2004;21:1531-8. https://doi.org/10.1023/B:PHAM.0000041444.06122.8d

31. Smith S, Lin K, Wilson J, Lunt D, Cross H. Starvation depresses acylglycerol biosynthesis in bovine subcutaneous but not intramuscular adipose tissue homogenates. Comp Biochem Physiol B Biochem Mol Biol 1998;120:165-74. https://doi.org/ 10.1016/S0305-0491(98)10005-6

32. Poulos SP, Dodson MV, Hausman GJ. Cell line models for differentiation: preadipocytes and adipocytes. Exp Biol Med 2010;235:1185-93. https://doi.org/10.1258/ebm.2010.010063

33.Smith SB, Gill CA, Lunt DK, Brooks MA. Regulation of fat and fatty acid composition in beef cattle. Asian-Australas J
Anim Sci 2009;22:1225-33. https://doi.org/10.5713/ajas.2009. r.10

34. Park H, Kaushik VK, Constant S, et al. Coordinate regulation of malonyl-CoA decarboxylase, sn-glycerol-3-phosphate acyltransferase, and acetyl-CoA carboxylase by AMP-activated protein kinase in rat tissues in response to exercise. J Biol Chem 2002;277:32571-7. https://doi.org/10.1074/jbc.M201692200

35. Kelly M, Keller C, Avilucea PR, et al. AMPK activity is diminished in tissues of IL-6 knockout mice: the effect of exercise. Biochem Biophys Res Commun 2004;320:449-54. https:// doi.org/10.1016/j.bbrc.2004.05.188

36. Orci L, Cook WS, Ravazzola M, et al. Rapid transformation of white adipocytes into fat-oxidizing machines. Proc Nat Acad Sci USA 2004;101:2058-63. https://doi.org/10.1073/ pnas. 0308258100

37. Sakoda $\mathrm{H}$, Ogihara T, Anai M, et al. Activation of AMPK is essential for AICAR-induced glucose uptake by skeletal muscle but not adipocytes. Am J Physiol Endocrinol Metab 2002;282: E1239-E44. https://doi.org/10.1152/ajpendo.00455.2001

38. Salt IP, Connell JM, Gould GW. 5-aminoimidazole-4-carboxamide ribonucleoside (AICAR) inhibits insulin-stimulated glucose transport in 3T3-L1 adipocytes. Diabetes 2000;49: 1649-56. https://doi.org/10.2337/diabetes.49.10.1649

39.Dagon Y, Avraham Y, Berry EM. AMPK activation regulates apoptosis, adipogenesis, and lipolysis by eIF2 $\alpha$ in adipocytes. Biochem Biophys Res Commun. 2006;340:43-7. https://doi. org/10.1016/j.bbrc.2005.11.159

40. Hawley SA, Davison M, Woods A, et al. Characterization of the AMP-activated protein kinase kinase from rat liver and identification of threonine 172 as the major site at which it phosphorylates AMP-activated protein kinase. J Biol Chem 1996;271:27879-87. https://doi.org/10.1074/jbc.271.44.27879 